\title{
Local anesthetic failure associated with inflammation: verification of the acidosis mechanism and the hypothetic participation of inflammatory peroxynitrite
}

\author{
Takahiro Ueno' \\ Hironori Tsuchiya ${ }^{2}$ \\ Maki Mizogami' \\ Ko Takakura' \\ 'Department of Anesthesiology, \\ Asahi University School of Dentistry, \\ Mizuho, Gifu, Japan; ${ }^{2}$ Department \\ of Dental Basic Education, Asahi \\ University School of Dentistry, \\ Mizuho, Gifu, Japan
}

\begin{abstract}
The presence of inflammation decreases local anesthetic efficacy, especially in dental anesthesia. Although inflammatory acidosis is most frequently cited as the cause of such clinical phenomena, this has not been experimentally proved. We verified the acidosis mechanism by studying the drug and membrane lipid interaction under acidic conditions together with proposing an alternative hypothesis. Liposomes and nerve cell model membranes consisting of phospholipids and cholesterol were treated at different $\mathrm{pH}$ with lidocaine, prilocaine and bupivacaine $(0.05 \%-0.2 \%, \mathrm{w} / \mathrm{v})$. Their membrane-interactive potencies were compared by the induced-changes in membrane fluidity. Local anesthetics fluidized phosphatidylcholine membranes with the potency being significantly lower at $\mathrm{pH} 6.4$ than at $\mathrm{pH} 7.4$ ( $\mathrm{p}<0.01)$, supporting the acidosis theory. However, they greatly fluidized nerve cell model membranes even at $\mathrm{pH} 6.4$ corresponding to inflamed tissues, challenging the conventional mechanism. Local anesthetics acted on phosphatidylserine liposomes, as well as nerve cell model membranes, at $\mathrm{pH} 6.4$ with almost the same potency as that at $\mathrm{pH} 7.4$, but not on phosphatidylcholine, phosphatidylethanolamine and sphingomyelin liposomes. Since the positively charged anesthetic molecules are able to interact with nerve cell membranes by ion-paring with anionic components like phosphatidylserine, tissue acidosis is not essentially responsible for the local anesthetic failure associated with inflammation. The effects of local anesthetics on nerve cell model membranes were inhibited by treating with peroxynitrite $(50 \mu \mathrm{M})$, suggesting that inflammatory cells producing peroxynitrite may affect local anesthesia.
\end{abstract}

Keywords: inflammatory acidosis, local anesthetic failure, membrane lipid interaction, hypothetic mechanism, inflammatory peroxynitrite

\section{Introduction}

Inflammatory diseases alter the pharmacokinetics and pharmacodynamics of various drugs, resulting in their decreased clinical effects and increased adverse effects (Slaviero et al 2003; Sattari et al 2003; Aitken et al 2006). Such an inflammation-induced alteration is well known especially in dental anesthesia. Local anesthetic failure or difficulty to obtain satisfactory analgesia commonly occurs in the situations of pulpitis and apical periodontitis (López and Diago 2006). The anesthetic efficacies of lidocaine and mepivacaine injections are remarkably affected in the teeth with irreversible pulpitis (Dunbar et al 1996; Reisman et al 1997). The presence of pulpitis has been estimated to cause inferior alveolar nerve block to fail in approximately $30 \%-45 \%$ of cases (Cohen et al 1993; Potočnik and Bajrović 1999). Although a variety of mechanistic hypotheses were proposed for explaining the decreased effects of local anesthetics in the presence of inflammation, the most cited is the theory that the acidosis of inflamed 
tissues reduces the anesthetic potencies of administered drugs (Meechan 1999; Becker and Reed 2006).

Since clinically used local anesthetics are structurally the tertiary amines with aromatic rings, they exist as charged and uncharged molecules with the relative amounts depending on their medium $\mathrm{pH}$ and $\mathrm{pKa}$ values. While both species are relevant to pharmacological activities, local anesthetics diffuse in uncharged form through nerve sheaths and penetrate into cell membranes to reach the cytoplasmic binding sites or receptors on transmembrane channels. In addition to the blockade of voltage-gated sodium channels, the mode of action of anesthesia includes the drug and membrane lipid interaction which induces the changes in membrane physicochemical property, fluidization or disordering (Jastak et al 1995; Frangopol and Mihǎilescu 2001). These pharmacological features, together with a correlation between anesthetic potency and lipid solubility (Covino 1986), strongly suggest that the drugs interact with membrane lipid bilayers to induce local anesthesia. Lactic acid and acidic by-products are increasingly produced and concentrated in and near inflamed tissues, causing the acidosis which lowers the tissue $\mathrm{pH}$ at least the order of 0.5-1.0 pH unit (Punnia-Moorthy 1987; de Backer 2003). The $\mathrm{pKa}$ values of almost local anesthetics in clinical use are larger than 7.5 (Jastak et al 1995). According to the Henderson-Hasselbalch equation ( $\log _{10}$ [uncharged drug]/ [charged drug] $=\mathrm{pH}-\mathrm{pKa}$ ), a greater proportion of administered drugs should be the charged molecules with much less membrane interactivity and permeability under acidic conditions corresponding to inflamed tissues. Therefore, local anesthetic effects would be decreased in the presence of inflammation, leading to the hypothetic mechanism based on tissue acidosis. This hypothesis seems to be so theoretical and understandable that it has been conventionally accepted despite being not experimentally confirmed.

The hydrophobic interaction underlies the effects of local anesthetics on lipid bilayers (Ohki and Ohshima 1996; Frangopol and Mihăilescu 2001; Tsuchiya et al 2005). However, the drug action on biomembranes is not identical to that speculated from the organic: aqueous phase partition. Unlike experimental membrane specimens with the simple lipid composition, nerve cell membranes consist of different phospholipid and sterol components (Svennerholm et al 1992). Their compositional variations greatly affect the membrane interactivities of drugs (Tsuchiya et al 2007).

Therefore, we attempted to verify the conventional acidosis mechanism for the local anesthetic failure associated with inflammation. We comparatively studied the interactions of local anesthetics with membrane lipids by lowering the reaction $\mathrm{pH}$ and varying the membrane lipid composition. Of particular interest were whether local anesthetics could change membrane fluidity at acidic $\mathrm{pH}$ by interacting with lipid bilayers and whether any of lipid components were specifically responsible for the possible membrane interaction. For this purpose, we used the liposome system in which reaction conditions and membrane lipids were readily manipulated to examine the influence of $\mathrm{pH}$ and the importance of individual lipids (Chatterjee and Agarwal 1988). Based on the verification results, we propose an alternative hypothesis which was speculated from the potential reactivity of peroxynitrite pathologically relevant to inflammation.

\section{Materials and methods Reagents}

Lidocaine, prilocaine and bupivacaine, all in hydrochloride salt form, were purchased from Sigma (St. Louis, MO, USA), and 1,2-dipalmitoylphosphatidylcholine (DPPC), 1-palmitoyl-2-oleoylphosphatidylcholine (POPC), 1-palmitoyl-2-oleoylphosphatidylethanolamine (POPE), 1-palmitoyl-2-oleoylphosphatidylserine (POPS) and sphingomyelin (SM) from Avanti Polar Lipids (Alabaster, AL, USA). Cholesterol, 1,6-diphenyl-1,3,5-hexatriene (DPH) and peroxynitrite were obtained from Wako Pure Chemicals (Osaka, Japan), Molecular Probes (Eugene, OR, USA) and Dojindo (Kumamoto, Japan), respectively. The concentration of peroxynitrite was spectrophotometrically determined according to manufacturer's directions, and then diluted to be $10 \mathrm{mM}$ with $0.1 \mathrm{M} \mathrm{NaOH}$. The prepared peroxynitrite solutions were stored at $-80^{\circ} \mathrm{C}$ and consumed within three weeks after preparation. Water of liquid chromatographic grade (Kishida, Osaka, Japan) and dimethyl sulfoxide of spectroscopic grade (Kishida) were used for preparing reagent solutions. All other chemicals were of the highest grade available commercially.

\section{Liposome preparation}

DPH-labeled liposomes of the lipid bilayer structure (total lipids of $0.14 \mathrm{mM}$ ) were prepared by hydrating the lipid dry film with $20 \mathrm{mM}$ sodium phosphate buffer of $\mathrm{pH} 7.4$ and 6.4 (Wako Pure Chemicals) containing $100 \mathrm{mM} \mathrm{KCl}$ as reported previously (Tsuchiya et al 2005). The molar ratio of DPH to membrane lipids was adjusted to be $1: 200$. The lipid composition of liposomal membranes was as follows: DPPC (100 mol\%), POPC and cholesterol (55: 45, mol\%), POPE and cholesterol (55:45, mol\%), POPS and cholesterol (55:45, mol\%), 
and SM and cholesterol (55: 45, mol\%). Nerve cell model membranes were prepared with POPC, POPE, POPS, SM and cholesterol (11: $16.5: 11: 16.5: 45$, mol\%) according to the composition of major membrane lipids of peripheral nerve cells (Svennerholm et al 1992).

\section{Membrane lipid interaction}

Local anesthetics dissolved in dimethyl sulfoxide $(20 \mu \mathrm{L})$ were added to the liposome preparations $(3.98 \mathrm{~mL})$ of $\mathrm{pH}$ 7.4 and 6.4 so that a final concentration was $0.2 \%(\mathrm{w} / \mathrm{v})$ for lidocaine, $0.2 \%(\mathrm{w} / \mathrm{v})$ for prilocaine and $0.05 \%(\mathrm{w} / \mathrm{v})$ for bupivacaine. The concentration of dimethyl sulfoxide was adjusted to be less than $0.5 \%(\mathrm{v} / \mathrm{v})$ of the total volume so as not to influence the membrane fluidity of liposomes. After reaction for $15 \mathrm{~min}$ at $37^{\circ} \mathrm{C}$, DPH fluorescence polarization was measured by an RF-540 spectrofluorometer (Shimadzu, Kyoto, Japan) equipped with a polarizer and a cuvette thermo-controller as reported previously (Tsuchiya 2001). Compared with control values (dimethyl sulfoxide vehicle added), the decrease of DPH polarization means the increase of fluidity (membrane fluidization) in the hydrocarbon cores of lipid bilayers, reflecting the acting site of tested drugs (Mizogami et al 2002). The potencies to interact with liposomal membranes were compared on the basis of the changing degree of polarization values relative to controls.

\section{Peroxynitrite treatment}

Local anesthetics dissolved in dimethyl sulfoxide $(20 \mu \mathrm{L})$ were added to the nerve cell model membrane preparations
(3.93 mL) of $\mathrm{pH} 7.4$ and 6.4 to be a final concentration of $0.2 \%(\mathrm{w} / \mathrm{v})$ for lidocaine, $0.2 \%(\mathrm{w} / \mathrm{v})$ for prilocaine and $0.05 \%(\mathrm{w} / \mathrm{v})$ for bupivacaine. Immediately after that, peroxynitrite in $0.1 \mathrm{M} \mathrm{NaOH}(50 \mu \mathrm{L})$ was added to be $50 \mu \mathrm{M}$ with vortex-mixing for $5 \mathrm{sec}$, followed by reaction for $15 \mathrm{~min}$ at $37^{\circ} \mathrm{C}$ to induce the membrane effects of local anesthetics. The corresponding volume of $0.1 \mathrm{M} \mathrm{NaOH}$ vehicle was added to controls. Thereafter, DPH polarization was measured as described above. The influence of peroxynitrite was evaluated by comparing the membrane-fluidizing effects of local anesthetics treated with and without peroxynitrite.

\section{Statistical analysis}

Results are expressed as mean $\pm \mathrm{SE}(\mathrm{N}=6-8)$. Data were statistically analyzed by Student's $t$-test (StatView 5.0; SAS Institute, Cary, NC, USA). A P value $<0.05$ was considered significant.

\section{Results}

Lidocaine, prilocaine and bupivacaine acted on DPPC liposomal membranes at $\mathrm{pH} 7.4$ to increase their fluidity as shown by DPH polarization decreases (Figure 1). At $\mathrm{pH}$ 6.4, however, their membrane-fluidizing effects were significantly weakened. Compared with $\mathrm{pH} 7.4$, the decreasing values of polarization were reduced to $30.8 \pm 1.2 \%$ for lidocaine, $32.5 \pm 0.9 \%$ for prilocaine and $32.5 \pm 0.5 \%$ for bupivacaine.

Even if the $\mathrm{pH}$ was lowered from 7.4 to 6.4 , local anesthetics more greatly fluidized nerve cell model

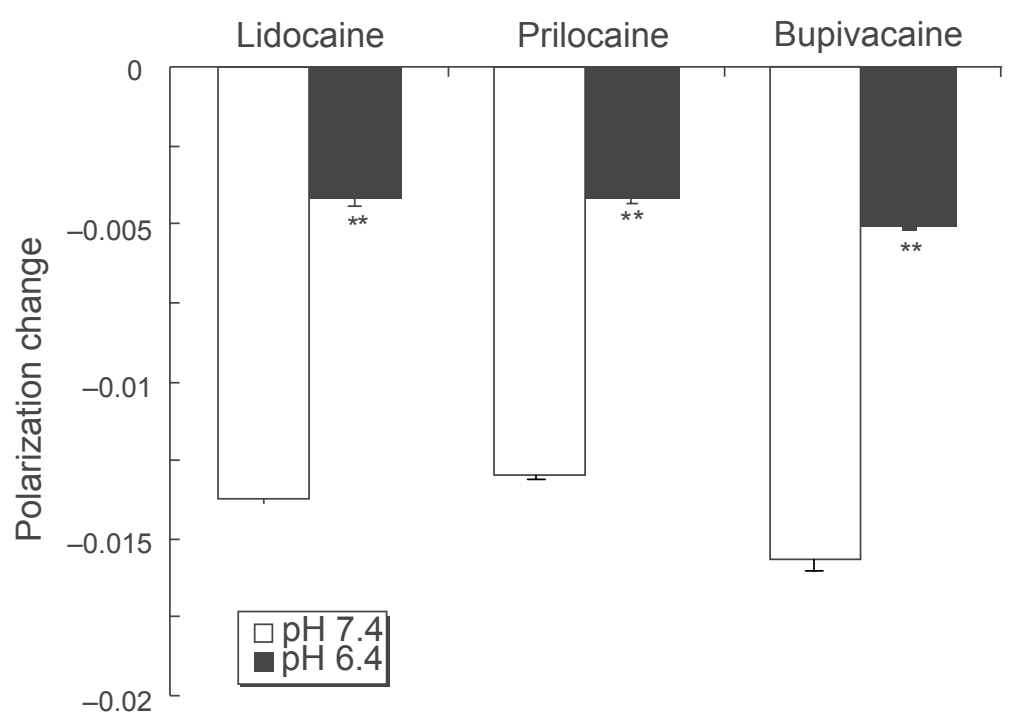

Figure I Effects of local anesthetics on DPPC liposomal membranes at different $\mathrm{pH}$. Lidocaine $(0.2 \%$, w/v), prilocaine $(0.2 \%$, w/v) and bupivacaine $(0.05 \%$, w/v) were reacted with DPPC liposomes for $15 \mathrm{~min}$ at $37^{\circ} \mathrm{C}$ at pH 7.4 and 6.4 , followed by $\mathrm{DPH}$ fluorescence polarization measurements. Each result represents mean $\pm \mathrm{SE}(\mathrm{N}=6-8)$. ${ }^{* *} \mathrm{p}<0.0 \mathrm{I}$, compared with $\mathrm{pH} 7.4$. 
membranes compared with DPPC liposomal membranes (Figure 2). While the polarization decreasing values at $\mathrm{pH} 6.4$ relative to $\mathrm{pH} 7.4$ were $69.6 \pm 2.1 \%$ for lidocaine, $70.5 \pm 1.9 \%$ for prilocaine and $71.8 \pm 2.9 \%$ for bupivacaine, their potencies to interact with nerve cell model membranes at $\mathrm{pH} 6.4$ were 2.2-2.3 times those with DPPC liposomal membranes.

The effects of $\mathrm{pH}$ lowering remarkably depended on the kind of membrane component phospholipids. The membrane-interactive potencies of lidocaine, prilocaine and bupivacaine were greatly diminished at $\mathrm{pH} 6.4$ in POPC, POPE and SM liposomal membranes (Figure 3). However, all the tested anesthetics fluidized POPS liposomal membranes at $\mathrm{pH} 6.4$ with almost the same potency as that at $\mathrm{pH}$ 7.4.

The relative potencies of local anesthetics to interact with liposomal membranes at $\mathrm{pH} 6.4$ to $\mathrm{pH} 7.4$ are shown in Table 1, together with the relative concentrations of uncharged molecules which were calculated by the Henderson-Hasselbalch equation using the $\mathrm{pKa}$ values of 7.9 for lidocaine, 7.8 for prilocaine and 8.1 for bupivacaine (Courtney 1980).

The fluidizing effects of lidocaine, prilocaine and bupivacaine on nerve cell model membranes were inhibited by treating with peroxynitrite (Figure 4). The inhibition occurred at both $\mathrm{pH} 7.4$ and $\mathrm{pH}$ 6.4, which showed no differences in inhibition potency.

\section{Discussion}

Representative anesthetics lidocaine, prilocaine and bupivacaine were subjected to the membrane interactions at clinically used concentrations (Jastak et al 1995). All of them fluidized DPPC liposomal membranes in $15 \mathrm{~min}$, being consistent with their onset time (Uckan et al 1998; Sun et al 1999). However, their membrane-interactive potencies were significantly decreased at $\mathrm{pH} 6.4$ which is almost comparable to inflamed tissue conditions (Punnia-Moorthy 1987). Such $\mathrm{pH}$-dependence may provide experimental support for the conventional mechanism based on tissue acidosis.

Local anesthetics must traverse ensheathing perineuria which are hydrophobic (lipoid) barriers against the drugs to reach nerve fibers. They also must penetrate into or across neuronal cell membranes consisting of lipid bilayers to exert their pharmacological activities. When blocking voltage-gated sodium channels, local anesthetics also permeate cell membranes to bind to the receptors. Inflammation causes metabolic acidosis which lowers the

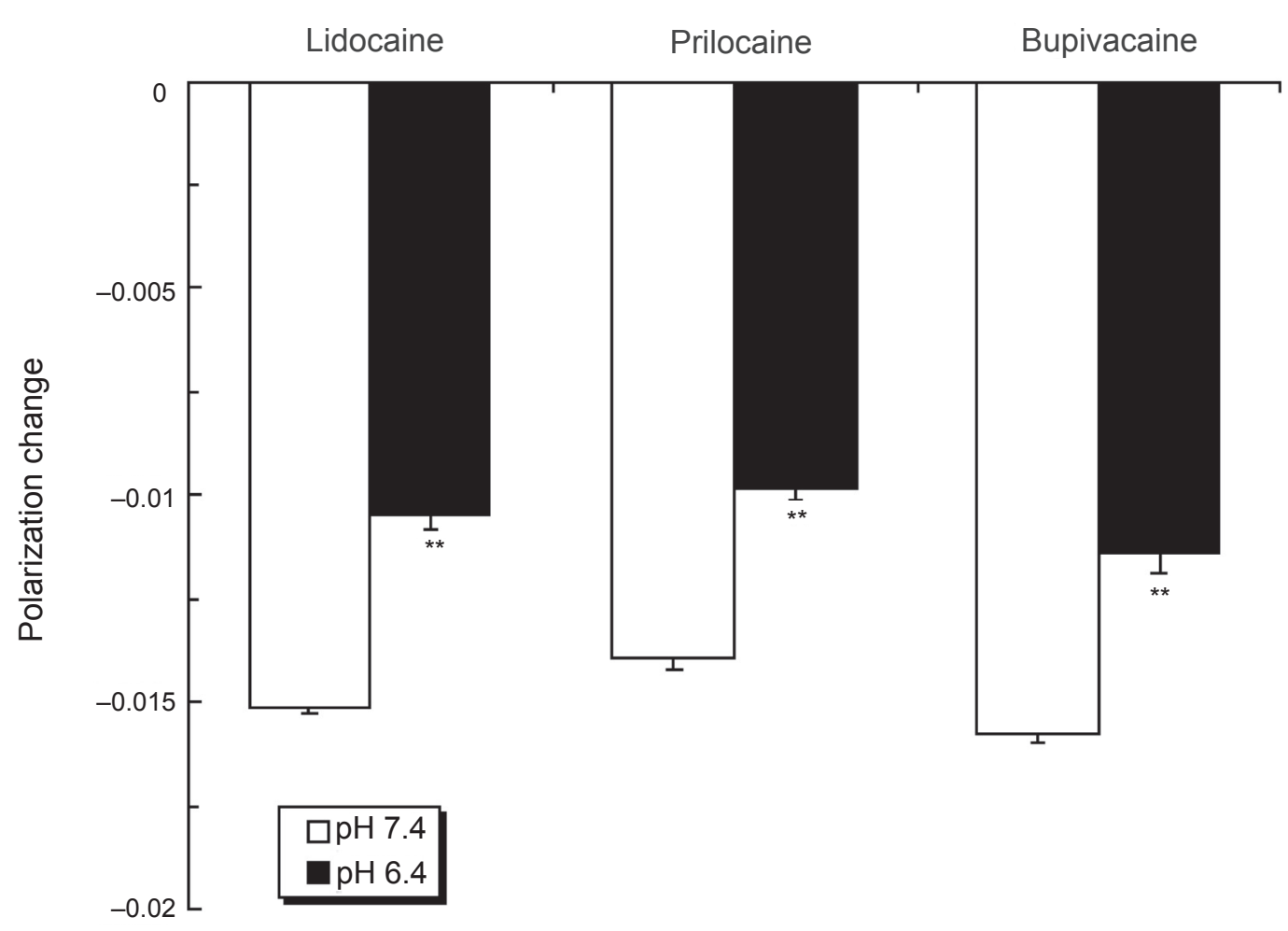

Figure 2 Effects of local anesthetics on nerve cell membranes at different $\mathrm{pH}$. Lidocaine $(0.2 \%, \mathrm{w} / \mathrm{v})$, prilocaine $(0.2 \%$, w/v) and bupivacaine $(0.05 \%$, w/v) were reacted with nerve cell model membranes for $15 \mathrm{~min}$ at $37^{\circ} \mathrm{C}$ at pH 7.4 and 6.4 , followed by DPH fluorescence polarization measurements. Each result represents mean $\pm \mathrm{SE}(\mathrm{N}=6-8)$. **p $<0.01$, compared with $\mathrm{pH} 7.4$. 
$\mathrm{pH} 7.4$

$\mathrm{pH} 6.4$

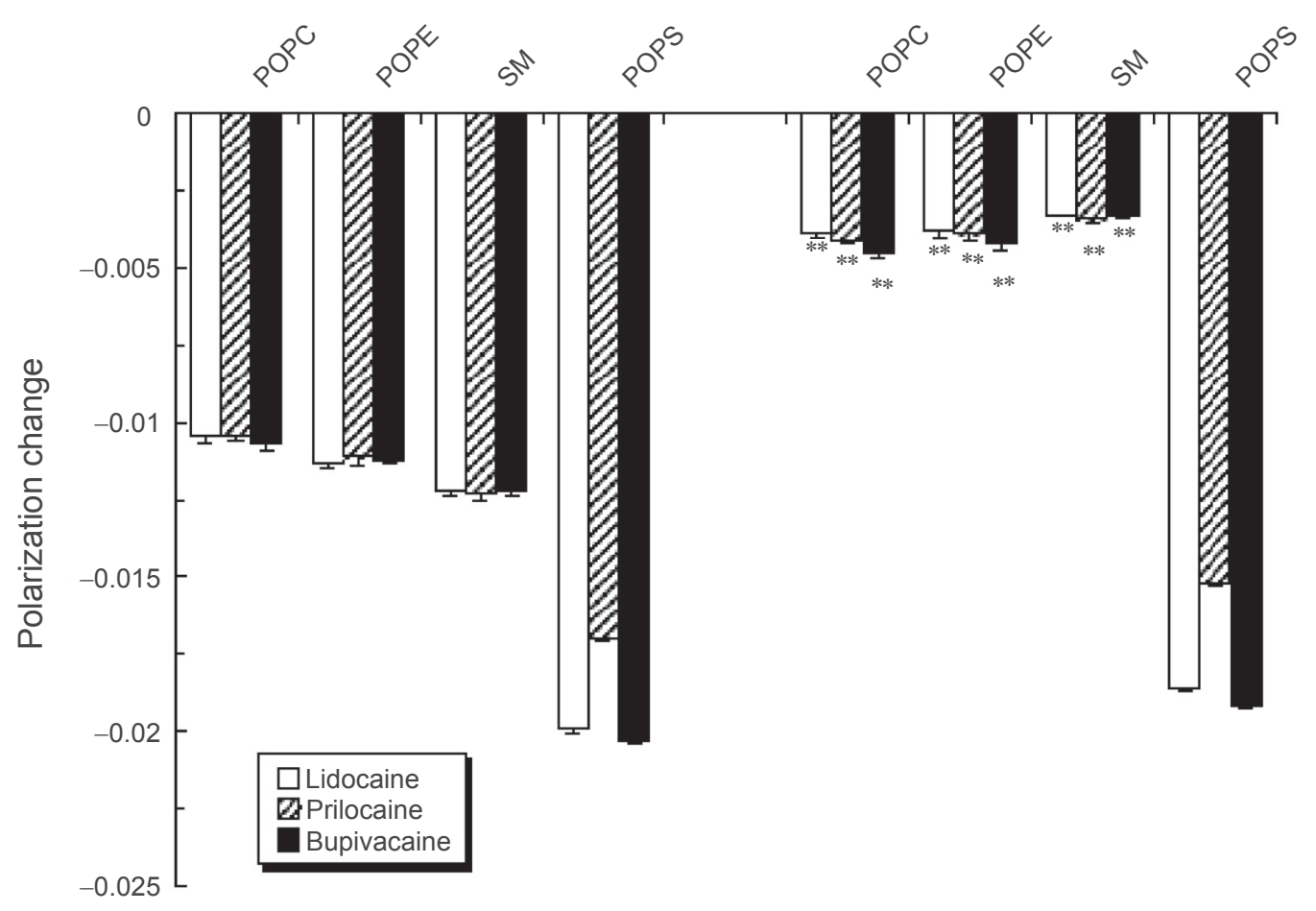

Figure 3 Effects of local anesthetics on liposomal membranes consisting of different phospholipids. Lidocaine $(0.2 \%, w / v)$, prilocaine $(0.2 \%$, w/v) and bupivacaine $(0.05 \%$, w/v) were reacted with POPC, POPE, SM or POPS liposomes for $15 \mathrm{~min}$ at $37^{\circ} \mathrm{C}$ at $\mathrm{pH} 7.4$ and 6.4 , followed by DPH fluorescence polarization measurements. Each result represents mean $\pm \mathrm{SE}(\mathrm{N}=6-8)$. ** $\mathrm{p}<0.0 \mathrm{I}$, compared with $\mathrm{pH} 7.4$.

pH of affected tissues (Punnia-Moorthy 1987; de Backer 2003). Such inflammatory conditions would alter the pharmacokinetics and pharmacodynamics of local anesthetics by reducing their interactivities with lipid bilayers and/or membrane lipids.

There is a systematic relationship between anesthetic potency and hydrophobicity to determine the membrane interactivity (Courtney 1980). The hydrophobicity of local anesthetics is characterized by their partition coefficients, usually in an octanol:buffer system (Strichartz et al 1990). While tertiary amine local anesthetics exist in uncharged (free base) or charged form depending on their $\mathrm{pKa}$ values and medium $\mathrm{pH}$, the uncharged molecules are much more membrane-interactive than the charged ones. As shown in Table 1, the relative potencies to interact with DPPC liposomal membranes decrease in all the tested drugs by lowering the $\mathrm{pH}$ from 7.4 to 6.4 , which is correlated to the decreasing relative concentrations of uncharged molecules.

Table I Relative concentrations of uncharged anesthetic molecules calculated by the Henderson-Hasselbalch equation and relative potencies to interact with different liposomal membranes (mean $\pm \mathrm{SE}, \mathrm{N}=6-8$ )

\begin{tabular}{|c|c|c|c|c|c|c|c|c|}
\hline & \multirow[b]{2}{*}{$\mathrm{pH}$} & \multirow[b]{2}{*}{$\begin{array}{l}\text { Relative concentration } \\
\text { of uncharged anesthetic } \\
\text { molecules }\end{array}$} & \multicolumn{6}{|c|}{ Relative potency to interact with } \\
\hline & & & $\begin{array}{l}\text { DPPC } \\
\text { liposome }\end{array}$ & $\begin{array}{l}\text { Nerve cell } \\
\text { model } \\
\text { membrane }\end{array}$ & $\begin{array}{l}\text { POPC and } \\
\text { cholesterol } \\
\text { liposome }\end{array}$ & $\begin{array}{l}\text { POPE and } \\
\text { cholesterol } \\
\text { liposome }\end{array}$ & $\begin{array}{l}\text { SM and } \\
\text { cholesterol } \\
\text { liposome }\end{array}$ & $\begin{array}{l}\text { POPS and } \\
\text { cholesterol } \\
\text { liposome }\end{array}$ \\
\hline \multirow[t]{2}{*}{ Lidocaine } & 7.4 & 100.0 & $100.0 \pm 0.2$ & $100.0 \pm 1.5$ & $100.0 \pm 2.8$ & $100.0 \pm 1.8$ & $100.0 \pm 1.8$ & $100.0 \pm 1.0$ \\
\hline & 6.4 & 12.8 & $29.8 \pm 1.1 * *$ & $70.2 \pm 2.1 * *$ & $36.7 \pm 0.8 * *$ & $34.1 \pm 1.6 * *$ & $27.5 \pm 0.4 * *$ & $98.2 \pm 0.7$ \\
\hline \multirow[t]{2}{*}{ Prilocaine } & 7.4 & 100.0 & $100.0 \pm 0.7$ & $100.0 \pm 1.8$ & $100.0 \pm 1.8$ & $100.0 \pm 2.4$ & $100.0 \pm 1.7$ & $100.0 \pm 0.6$ \\
\hline & 6.4 & 13.5 & $31.5 \pm 0.8^{* *}$ & $71.1 \pm 1.9 * *$ & $38.9 \pm 0.9 * *$ & $35.5 \pm 1.8 * *$ & $27.6 \pm 0.8 * *$ & $94.1 \pm 0.9 * *$ \\
\hline \multirow[t]{2}{*}{ Bupivacaine } & 7.4 & 100.0 & $100.0 \pm 1.1$ & $100.0 \pm 1.4$ & $100.0 \pm 2.3$ & $100.0 \pm 1.3$ & $100.0 \pm 2.0$ & $100.0 \pm 0.6$ \\
\hline & 6.4 & 11.8 & $31.4 \pm 0.5^{* *}$ & $72.4 \pm 2.9 * *$ & $42.1 \pm 2.0 * *$ & $37.5 \pm 1.5 * *$ & $27.4 \pm 1.1 * *$ & $99.5 \pm 0.6$ \\
\hline
\end{tabular}

**p $<0.01$ compared with $\mathrm{pH} 7.4$. 


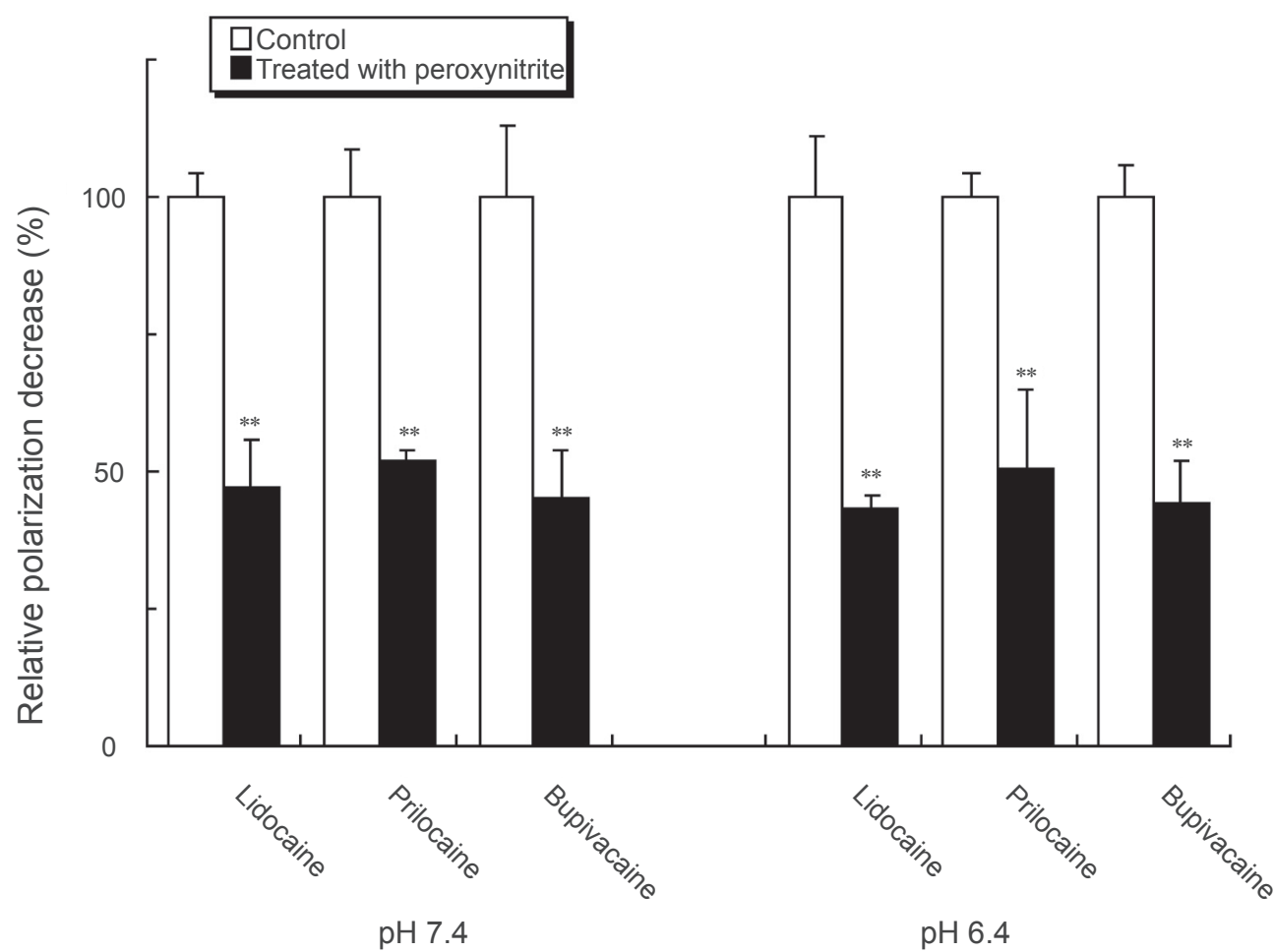

Figure 4 Influence of peroxynitrite on local anesthetic membrane effects. Lidocaine $(0.2 \%, w / v)$, prilocaine $(0.2 \%$, w/v) and bupivacaine $(0.05 \%$, w/v) were treated with $50 \mu \mathrm{M}$ peroxynitrite for $5 \mathrm{sec}$ at $\mathrm{pH} 7.4$ and 6.4. Their effects on nerve cell model membranes were determined after reaction for 15 min at $37{ }^{\circ} \mathrm{C}$ by measuring $\mathrm{DPH}$ fluorescence polarization. Each result represents mean $\pm \mathrm{SE}(\mathrm{N}=6-8)$. ${ }^{* *} \mathrm{p}<0.01$, compared with control (not treated with peroxynitrite).

The effects of lidocaine, prilocaine and bupivacaine on nerve cell model membranes at $\mathrm{pH} 6.4$ were much greater than presumed from their relative concentrations of uncharged molecules (Table 1). Although the rank order is different between relative potency and concentration, this is interpretable by the difference in hydrophobicity of local anesthetics. The hydrophobic interaction with phosphatidylcholine membranes is estimated to be prilocaine $<$ lidocaine $<$ bupivacaine in increasing order of intensity based on their chromatographic behaviors in the reversedphase partition system (Tsuchiya et al 2005). The partition coefficients are greatest in the order of prilocaine $<$ lidocaine $<<$ bupivacaine for both uncharged and charged molecules (Strichartz et al 1990). The results of nerve cell model membranes never support the acidosis mechanism, indicating that the tissue acidification is not essentially responsible for the decreased effects of local anesthetics in the presence of inflammation.

Unlike DPPC liposomal membranes consisting of phosphatidylcholine alone, nerve cell model membranes were prepared with different phospholipids (POPC, POPE, POPS and SM) and cholesterol to resemble peripheral nerve cells (Svennerholm et al 1992). Such lipid composition may explain why local anesthetics are able to interact with membrane lipids under inflammatory acidic conditions. As well as DPPC liposomes, liposomal membranes consisting of POPC, POPE and SM showed much less fluidization at $\mathrm{pH} 6.4$ compared with $\mathrm{pH}$ 7.4. However, only POPS liposomal membranes were significantly fluidized even at pH 6.4 by lidocaine, prilocaine and bupivacaine despite that their charged molecules predominated. With respect to structural difference of these phospholipids, DPPC, POPC, POPE and SM are zwitterionic, whereas POPS is acidic. Positively charged (cationic) drugs show much higher affinity to acidic (anionic) phospholipids like POPS compared with zwitterionic ones (de Wolf et al 1990; Tsuchiya et al 2007). Not only uncharged but also charged anesthetics are able to interact with lipid bilayers, the former deeply in the hydrophobic core, but the latter in the head-group regions of phospholipids (Pasenkiewicz-Gierula et al 2003). Local anesthetics in charged form electrostatically interact with the negatively charged sites in membranes at $\mathrm{pH}$ lower than the $\mathrm{pKa}$ values and their adsorbed amounts depend on the membrane surface charge (Ohki and Ohshima 1996). In this study, local anesthetics with pKa over 7.8 showed less fluidizing effects on DPPC, POPC, POPE and SM liposomal membranes at $\mathrm{pH} 6.4$ as the uncharged molecules decreased. On the other hand, their effects on POPS liposomal membranes 
were significantly great even at $\mathrm{pH} 6.4$, contradicting to the relative decrease of uncharged molecules, but correlating to the relative increase of charged molecules. As known in certain amphiphilic drugs (Štolc et al 1989), the cationic moieties of local anesthetics possibly pair with the anionic head-groups of acidic phospholipids to form the seemingly uncharged ion-pairs, which could penetrate into lipid bilayers and modify membrane fluidity. Acidic phosphatidylserine is referred to as a counter-ion to pair with positively charged anesthetics.

Local anesthetics have been verified to interact with nerve cell membranes at the $\mathrm{pH}$ corresponding to inflammatory acidosis. Tissues can buffer the excess acidity (Wennberg et al 1982) and such buffering is more potent in inflamed tissues (Punnia-Moorthy 1988). These pathophysiological features are also unfavorable to the conventional mechanism based on tissue acidosis, requiring an alternative theory for the local anesthetic failure associated with inflammation.

Inflammatory cells produce peroxynitrite (Ródenas et al 1995), which has been implicated in the pathogenesis of various diseases including inflammation (Demiryürek et al 1998). Inflamed tissues are characterized by the production of nitric oxide and superoxide anion which react to form peroxynitrite. Inflammatory diseases influence the effects of different drugs due to the formation of nitric oxide (Mayo et al 2000; Kulmatycki et al 2001). Several local anesthetics, including lidocaine and bupivacaine, react with peroxynitrite (Gunaydin and Demiryurek 2001; Günaydin and Demiryürek 2003). Peroxynitrite is also able to inhibit $\mathrm{Na}^{+} / \mathrm{K}^{+}$-ATPase activity through the modification of membrane fluidity (Muriel and Sandoval 2000). Therefore, our hypothesis is that inflammatory peroxynitrite may interact with local anesthetics to affect their membrane interactivities.

In the membrane interaction experiments, peroxynitrite has been revealed to inhibit the anesthetic-induced fluidization of nerve cell model membranes. The reactivity of peroxynitrite is greater at acidic to neutral $\mathrm{pH}$ than at alkaline $\mathrm{pH}$ (Radi et al 1991). While local anesthetics were reacted with $50 \mu \mathrm{M}$ peroxynitrite for $5 \mathrm{sec}$ at $\mathrm{pH} 7.4$ and 6.4 , these experimental conditions are not in conflict with the peroxynitrite exposure by activated inflammatory cells (Ischiropoulos et al 1992).

Since venules and capillaries are dilated in inflamed tissues, the increased blood flow due to vasodilatation would promote the absorption and removal of local anesthetics from their administered sites (Punnia-Moorthy 1988; Jastak et al 1995). The presence of inflammation modifies the activities of sensory nerves and ion channels to possibly induce afferent hyperexcitability and hyperalgesia (Flake and Gold 2005; Wang et al 2007). In addition to these pathophysiological changes, it is hypothesized that inflammatory peroxynitrite could participate in the decrease of local anesthetic effects.

In conclusion, inflammatory acidosis is not as important for the decreased efficacy of local anesthesia as recognized conventionally. As a novel mechanistic hypothesis, peroxynitrite relevant to inflammation may interact with local anesthetics to modify their pharmacological activities.

\section{Acknowledgments}

This study was partly supported by a Grant-in-Aid for Scientific Research 20592381 (to H.T.) from the Japan Society for the Promotion of Science.

\section{Disclosures}

None of the authors disclose conflicts of interest.

\section{References}

Aitken AE, Richardson TA, Morgan ET. 2006. Regulation of drugmetabolizing enzymes and transporters in inflammation. Annu Rev Pharmacol Toxicol, 46:123-49.

Becker DE, Reed KL. 2006. Essentials of local anesthetic pharmacology. Anesth Prog, 53:98-109.

Chatterjee SN, Agarwal S. 1988. Liposomes as membrane model for study of lipid peroxidation. Free Radic Biol Med, 4:51-72.

Cohen HP, Cha BY, Spångberg LS. 1993. Endodontic anesthesia in mandibular molars: a clinical study. J Endod, 19:370-3.

Courtney KR. 1980. Structure-activity relations for frequency-dependent sodium channel block in nerve by local anesthetics. J Pharmacol Exp Ther, 213:114-9.

Covino BG. 1986. Pharmacology of local anaesthetic agents. Br J Anaesth, 58:701-16.

de Backer D. 2003. Lactic acidosis. Minerva Anestesiol, 69:281-4.

de WolfFA, Maliepaard M, van Dorsten F, et al. 1990. Comparable interaction of doxorubicin with various acidic phospholipids results in changes of lipid order and dynamics. Biochim Biophys Acta, 1096:67-80.

Demiryürek AT, Cakici I, Kanzik I. 1998. Peroxynitrite: a putative cytotoxin. Pharmacol Toxicol, 82:113-7.

Dunbar D, Reader A, Nist R, et al. 1996. Anesthetic efficacy of the intraosseous injection after an inferior alveolar nerve block. $J$ Endod, 22:481-6.

Flake NM, Gold MS. 2005. Inflammation alters sodium currents and excitability of temporomandibular joint afferents. Neurosci Lett, 384:294-9.

Frangopol PT, Mihăilescu D. 2001. Interactions of some local anesthetics and alcohols with membranes. Colloids Surf B Biointerfaces, $22: 3-22$.

Gunaydin B, Demiryurek AT. 2001. Interaction of lidocaine with reactive oxygen and nitrogen species. Eur J Anaesthesiol, 18:816-22.

Günaydin B, Demiryürek AT. 2003. Effects of tetracaine and bupivacaine on chemiluminescence generated by formyl-methionyl-leucylphenylalanine-stimulated human leukocytes and cell-free systems. Int Immunopharmacol, 3:757-64.

Ischiropoulos H, Zhu L, Beckman JS. 1992. Peroxynitrite formation from macrophage-derived nitric oxide. Arch Biochem Biophys, 298:446-51. 
Jastak JT, Yagiela JA, Donaldson D. 1995. Local Anesthesia of the Oral Cavity. Philadelphia: WB Saunders.

Kulmatycki KM, Abouchehade K, Sattari S, et al. 2001. Drug-disease interactions: reduced $\beta$-adrenergic and potassium channel antagonist activities of sotalol in the presence of acute and chronic inflammatory conditions in the rat. Br J Pharmacol, 133:286-94.

López AB, Diago MP. 2006. Failure of locoregional anesthesia in dental practice. Review of the literature. Med Oral Patol Oral Cir Bucal, 11:E510-3.

Mayo PR, Skeith K, Russell AS, et al. 2000. Decreased dromotropic response to verapamil despite pronounced increased drug concentration in rheumatoid arthritis. Br J Clin Pharmacol, 50:605-13.

Meechan JG. 1999. How to overcome failed local anaesthesia. Br Dent J, 186:15-20.

Mizogami M, Tsuchiya H, Harada J. 2002. Membrane effects of ropivacaine compared with those of bupivacaine and mepivacaine. Fundam Clin Pharmacol, 16:325-30.

Muriel P, Sandoval G. 2000. Nitric oxide and peroxynitrite anion modulate liver plasma membrane fluidity and $\mathrm{Na}^{+} / \mathrm{K}^{+}$-ATPase activity. Nitric Oxide, 4:333-42.

Ohki S, Ohshima H. 1996. Distribution of local anesthetics in lipid membranes. Colloids Surf B Biointerfaces, 5:291-305.

Pasenkiewicz-Gierula M, Róg T, Grochowski J, et al. 2003. Effects of a carane derivative local anesthetic on a phospholipid bilayer studied by molecular dynamics simulation. Biophys $J, 85: 1248-58$.

Potočnik I, Bajrović F. 1999. Failure of inferior alveolar nerve block in endodontics. Endod Dent Traumatol, 15:247-51.

Punnia-Moorthy A. 1987. Evaluation of $\mathrm{pH}$ changes in inflammation of the subcutaneous air pouch lining in the rat, induced by carrageenan, dextran and Staphylococcus aureus. J Oral Pathol, 16:36-44.

Punnia-Moorthy A. 1988. Buffering capacity of normal and inflamed tissues following the injection of local anaesthetic solutions. Br J Anaesth, 61:154-9.

Radi R, Beckman JS, Bush KM, et al. 1991. Peroxynitrite-induced membrane lipid peroxydation: the cytotoxic potential of superoxide and nitric oxide. Arch Biochem Biophys, 288:481-7.

Reisman D, Reader A, Nist R, et al. 1997. Anesthetic efficacy of the supplemental intraosseous injection of $3 \%$ mepivacaine in irreversible pulpitis. Oral Surg Oral Med Oral Pathol, 84:676-82.
Ródenas J, Mitjavila MT, Carbonell T. 1995. Simultaneous generation of nitric oxide and superoxide by inflammatory cells in rats. Free Radic Biol Med, 18:869-75.

Sattari S, Dryden WF, Eliot LA, et al. 2003. Despite increased plasma concentration, inflammation reduces potency of calcium channel antagonists due to lower binding to the rat heart. Br J Pharmacol, 139:945-54.

Slaviero KA, Clarke SJ, Rivory LP. 2003. Inflammatory response: an unrecognised source of variability in the pharmacokinetics and pharmacodynamics of cancer chemotherapy. Lancet Oncol, 4:224-32.

Štolc S, Nemček V, Szöcsová H. 1989. Local anesthetics: lipophilicity, charge, diffusion and site of action in isolated neuron. Eur J Pharmacol, 164:249-56.

Strichartz GR, Sanchez V, Arthur GR, et al. 1990. Fundamental properties of local anesthetics. II. Measured octanol:buffer partition coefficients and $\mathrm{pK}_{\mathrm{a}}$ values of clinically used drugs. Anesth Analg, 71:158-70.

Sun R, Hamilton RC, Gimbel HV. 1999. Comparison of 4 topical anesthetic agents for effect and corneal toxicity in rabbits. $J$ Cataract Refract Surg, 25:1232-6.

Svennerholm L, Boström K, Fredman P, et al. 1992. Membrane lipids of human peripheral nerve and spinal cord. Biochim Biophys Acta, 1128:1-7.

Tsuchiya H, Mizogami M, Takakura K. 2005. Reversed-phase liquid chromatographic retention and membrane activity relationships of local anesthetics. J Chromatogr A, 1073:303-8.

Tsuchiya H, Mizogami M, Ueno T, et al. 2007. Interaction of local anaesthetics with lipid membranes under inflammatory acidic conditions. Inflammopharmacology, 15:164-70.

Tsuchiya H. 2001. Structure-specific membrane-fluidizing effect of propofol. Clin Exp Pharmacol Physiol, 28:292-9.

Uckan S, Guler N, Sumer M, et al. 1998. Local anesthetic efficacy for oral surgery: Comparison of diphenhydramine and prilocaine. Oral Surg Oral Med Oral Pathol Oral Radiol Endod, 86:26-30.

Wang J-G, Strong JA, Xie W, et al. 2007. Local inflammation in rat dorsal root ganglion alters excitability and ion currents in small diameter sensory neurons. Anesthesiology, 107:322-32.

Wennberg E, Haljamäe H, Edwall G, et al. 1982. Effects of commercial $(\mathrm{pH} \sim 3.5)$ and freshly prepared $(\mathrm{pH} \sim 6.5)$ lidocaine-adrenaline solutions on tissue pH. Acta Anaesth Scand, 26:524-7. 